\title{
'N EIE SUID-AFRIKAANSE REG
}

Wanneer ons die eenvoudige vraag stel: wie is meerderjariges volgens die Suid-Afrikaanse reg, het ons met ' $n$ algemene en 'n besondere probleem van regsvinding te doen. Dit is 'n algemene probleem omdat net so 'n 
vraag ook ten aansien van enige ander land gevra kan word; en dit is vir ons 'n besondere omdat dit hier spesifiek oor ons land en sy reg gaan.

Byna vanselfsprekend sal geantwoord word: die Suid-Afrikaanse reg self sal aandui wie daarvolgens meerderjariges is. Veel verder bring dit ons nie, want meteen kan die volgende vraag kom: waar of waarin vind ek die Suid-Afrikaanse reg, of waaruit blyk dit; en wat is dan per slot van rekening „die reg" wat hier met ,Suid-Afrikaanse" gekwalifiseer word?

Om op enige van hierdie vrae antwoorde te gee, is geen geringe taak nie. Maar behoorlike antwoorde daarop is in alle geval noodsaaklike voorvereistes vir die beantwoording juis van die eerste vraag. Immers, dit spreek vanself dat, wat oor meerderjariges in die Suid-Afrikaanse reg meegedeel word, geskied juis in die lig van wat onder ,die reg" soos gekwalifiseer deur „Suid-Afrikaanse" verstaan word.

By die bepaling van die betekenisinhoud van die begrip „die reg” vir die beantwoording van eersgenoemde vraag, is daar meer as een probleem wat opgelos moet word. Die eerste probleem is geskep deur die literatuur oor die algemeen oor juis daardie begrip, en die indeling van daardie literatuur in verskillende rigtings of skole. Hierdie probleem bring met sig mee oorweging van die vraag of ons uit daardie skole 'n keuse moet maak, dan wel of ons 'n eie, suiwerder benadering daarop moet nahou. Sodanige oorweging hou nie net in deeglike kennis van die verskillende skole nie, maar ook by voorbaat 'n eie uitgangspunt. Motivering vir die aanhang van die een of die ander, bring op sy beurt weer mee die aanvulling van die algemene literatuur oor die reg, tot, kan moedeloos gevra word, watter nut?

Wie ook al oor ,die reg" geskryf het, wanneer hy ook al geskryf het, en van watter taal hy hom ook al as middel bedien het, dit kan van hom gesê word dat hy, tensy hy iemand was wat ' $\mathrm{n}$ ander se standpunt openlik en klakkeloos nagevolg het, of bedektelik plagiaat gepleeg het, sodanige eie mening daarop nagehou het, of andere se menings sodanig tot 'n skynbaar nuwe mening saamgeflans het, dat die persoon wat vandag uit die algemene literatuur oor ,die reg" moet wys word wat dit is, sonder meer kan verklaar dat dit 'n onbegonne taak is, omdat daar net soveel omskrywings, formulerings, uitgangspunte en vooropgesette doelstellings as skrywers is. Die algemene literatuur oor „die reg", jus, droit, Recht, diritto, law-'n groteske en afskrikwekkende produk van eeue--kan haas nie oorsien word nie.

Voeg daarby dat diegene wat wel oor die onderwerp geskryf het, nie net juriste was nie-juriste het in alle geval betreklik laat wysgerig geraak oor die reg-dan is die populêre opvatting omtrent die reg en die bespotting van die juris nie geregverdig nie. Filosowe, teoloë, sosioloë, historici, 
letterkundiges, politici, geskooldes in die staatsleer en talle ander het hulle oor die onderwerp uitgelaat, elk vanuit sy eie oogpunt, vakkundig en andersins. Sommige van hulle het dit uit die opregte oortuiging dat „die reg" gesoek en gevind is, gedoen; ander miskien ook so, maar tog smalend en afbrekend; en nog andere weer eg onkundig. Baie wat oor die onderwerp gesê is, was ook gevaarlik, afgesien van onwaar. Waar die onderwerp vanuit bloot praktiese, of historiese, filosofiese, godsdienstige, etiese, of politieke en talle ander rigtings benader is, kan seer seker geen eenstemmigheid onder die skrywers verwag word nie.

Nie net het Faust met die reg en die regswetenskap die spot gedryf by monde van die duiwel as regspreker nie, maar Erasmus laat die sotheid dieselfde funksie vervul in sy Laus Stultitiae. Kant, wat self bespiegelinge oor die reg gehou het-en vir homself in alle geval klaarheid oor die begripsinhoud daarvan verkry het-het nietemin met sy verklaring: „Noch suchen die Juristen eine Definition zu ihrem Begriffe von Recht," iets gesê wat, juis ook vanweë sy bespiegelinge oor die reg, vandag nog die waarheid isen nie net vir juriste nie, maar ook vir filosowe! Toe Bentham verklaar het dat: „In the map of science, the department of judicial science remains to this hour a perfect blank. Power has hitherto kept it in a state of wilderness; reason has never visited it", het hy bes moontlik nie gedink dat juis sy eie opvattings oor die reg sou maak dat die wildernis vergroot is en die rede 'n ander rol gekry het nie. Von Kirchmann het met sy opvatting dat die voorwerp van die reg nooit begryp kan word nie, omdat dit voortdurend verander, aan positiewe wette gebonde is en onderworpe is aan willekeur, negatief opgetree. Sy berugte uitlating: „Drei berichtigenden Worte des Gesetzgebers, und ganze Bibliotheken werden zu Makulatur", kan ongelukkig nie so vertolk word dat hy die wetgewer was en die ganse literatuur oor ,die reg" die biblioteke nie. Na hom is daar éérs oor die aangeleentheid geskryf. Mens sou geneig wees om te sê: „Hätte Lyra nicht über die Bibel geschrieben, wär mancher Doktor ein Esel geblieben"! Met al die geskrifte oor die reg, is ons seker nie uit die wildernis uit nie. Weliswaar kan dit nou weer so wees dat baie moderne wysgerige stelsels ,een rechtsphilosophische uitbouw missen", soos Kranenburg meen, en dat daar 'n duidelike anti-juridiese gesindheid te bespeur is, ,,die het recht als een van de meest conventionele menselijke geesteswerkzaamheden zo ver mogelijk uit de nabijheid van de philosophie verwijst". Dit vergemaklik nie ons taak nie, want daarteenoor word juis, al is dit dan by wyse van uitsondering op wat omtrent moderne wysgerige stelsels gesê is, geleer dat dit net die algemene wysbegeerte is wat, as wetenskap van die totaliteit, kan leer wat die volle 
tydelike werklikheid is, waarby die regsaspek van die werklikheid ingesluit is, en ons so die reg kan laat begryp. Ons is en bly daarmee nog aangewese op kennisname van wat oor die reg geskryf is en die skole of rigtinge wat in daardie geskrifte geopenbaar sou gewees het. Die vraag of ons maar net daaruit moet kies dan wel of ons 'n eie rigting moet inslaan, bly ook nog.

'n Keuse tussen rigtings word bemoeilik omdat die volgende ook so waar is van die regsliteratuur oor die algemeen en dit daarom so uitsien soos wel die geval is: „Whilst natural scientists in their examination of, for instance, electricity and its effects, or medical scientists investigating our deadly diseases, as a rule take good care that nothing is divulged to the public until it has been carefully scrutinized, so as not to evoke false hopes and expectations, and whilst they always modestly impress on the public, when they speak at all, how limited their results are and how dangerous it would be to jump to conclusions, the social philosophers, on the other hand, whether it be Karl Marx or the liberal economists, express themselves with a certainty and sufficiency as if their systems were scientifically infallible, although the truth is that at best they are quite improvable." Hierdie uitlating van die Deense juris Kruse openbaar self 'n eie benadering, nl. een gerig teen die liberale skool, of wel ook een wat, wanneer mens die hele werk lees, geklassifiseer sou kon word as 'n empiries-sosiologiese benadering. Op dié manier kom ons weer uit by dieselfde deur waar ons ingegaan het, niks wyser omtrent ,die reg" nie, altans nie uit die algemene literatuur daaroor nie, omdat ook diegene wat van mekaar varskil, nie die moeite doen om die een die ander se standpunt te ken en so tot die uiteindelike waarheid te kom nie. Daar is ' $n$ duidelike neiging in Holland byvoorbeeld om slegs te verklaar dat hierdie of daardie skrywer ' $n$ totaal ander rigting as dié van Dooyeweerd voorstaan-en daarmee geen verdere aandag aan Dooyeweerd se rigting te skenk nie. Die vraag is dus nog: wat staan ons hier te lande te doen?

Die tweede probleen hou verband met hierdie vraag: gestel ons in Suid-Afrika sou een of ander rigting soos geopenbaar in die algemene literatuur oor ,die reg" voorstaan, kan ons dan sê dat dit "Suid-Afrikaans” is? Moét hierdie gekose rigting "Suid-Afrikaans" wees? En presies wat is dan die onderskeidende van "Suid-Afrikaans"?

Mens sou die tweede probleem ook anders kon benader. Gestel ,die Suid-Afrikaanse reg" sou wel aan ons toon wat onder ,die reg" verstaan word, moet ons dit dan net so aanvaar? Of moet ons dit verwerp in die lig van een of ander rigting of skool? Kan die formulering van die begrip „die reg" soos ons dit in ,die Suid-Afrikaanse reg” vind, geklassifiseer word onder die een of ander rigting of skool, en indien wel, moet dit maar net daar- 
by bly? Kortom, as juis diegene wat oor ,die Suid-Afrikaanse reg" geskryf het toon dat hulle 'n onaanneemlike betekenis aan die begrip ,die reg" gee, moet ons dan daarop verbeter, en kan daardie verbetering ,,Suid-Afrikaans" word of wees?

'n Derde probleem is natuurlik of dit moontlik is om, aan die hand van wat daar oor ,,die Suid-Afrikaanse reg" geskryf is, te bepaal of daar 'n algemeen aanvaarde of een betekenis aan die begrip, ,die reg" gegee is, en ook 'n algemeen aanvaarde en een betekenis aan die woorde "Suid-Afrikaans" gegee is. Anders gestel, ons derde probleem is om 'n Suid-Afrikaansregswetenskaplike formulering van ,die reg" te gee. Dit is op sigself 'n moeilike taak wat inderdaad nog nie aangepak is nie. Die literatuur wat spesifiek daaroor gaan, is nie net uiters karig nie, maar dit openbaar ook nog, min soos dit is, invloede wat meteen die vraag kan laat ontstaan of dit wat gesê is, wel „Suid-Afrikaans" is. Laat my net hierdie twee voorbeelde noem om die aangeleentheid toe te lig.

Wille, wie se Principles of South African Law nie net 'n bekende handboek is nie, maar ook een is wat reeds 'n paar uitgawes beleef het, haal in die tweede uitgawe van sy werk by sy omskrywing van "national law", wat hy noem 'n ,,collection of rules, the object of which is to maintain order in a state" (b. 2), en wat ook genoem word positiewe reg of ,law of the state", as outoriteite vir sy omskrywing en bespreking die volgende skrywers aan: Keith, Vinogradoff, Austin, De Groot, Salmond, Hibbert en Odgers. Dit is skrywers uit verskillende tydperke en verskillende lande, met verskillende uitgangspunte. Indirek haal hy ook by Holland, Allen, Ihering, Stammler, Dicey, Voet en Blackstone. Dieselfde opmerking kan ook van hulle gemaak word. Terselfdertyd verwys hy na die Corpus Juris Civilis, die Suid-Afrikawet van 1909 en ons hof beslissings. Al hierdie ,,bronne” gebruik hy om nou die begrip ,national law" te omskryf en een en ander mee te deel oor die handhawing daarvan, die ontstaan daarvan en die inhoud daarvan. Dit dien dan as inleiding tot 'n studie van ons eie ,national law', wat hy verder noem "South African law".

Om wat hy noem die wesenlike kenmerke, bestanddele, elemente of grondslae van ,national law" te verduidelik, haal hy weer die volgende bronne aan, afgesien van 'n paar wat hy reeds genoem het: die Evangelie van Mattheüs en dié van Lukas, die Encyclopedia Brittanica, 'n Statement of the Episcopal Synod of South Africa (van Oktober 1943), Roscoe Pound, Kohler, Van Leeuwen, Wet 5 van 1910, Wessels, Huber, Scoble, Burge, Markby, Mackeurtan en Van der Linden. 
Kom hy by die ontstaan van die ,national law", beroep hy hom op van die reeds genoemde bronne plus nog sekere Uniewette, Halsbury, ou plakkate, Schorer, Van der Keesel, Zoezius, Carpzovius, Lambert en Lightwood. Ook hier bly die verskeidenheid van opvatting, land en tydperk.

Ten einde die verskil uit te bring tussen ,,national law" en , laws other than national law" en die invloed van laasgenoemde op eersgenoemde aan te toon, haal hy nie net soortgelyke uiteenlopende bronne soos dié reeds genoem, aan nie, maar voeg hy nog by Cicero, Locke, Aristoteles, Bryce, Hooker, Hobbes, Thomas Aquinas, Engelse vonnisse, Berolzheimer, Del Vecchio, Macdonnell, McGregor, Maine, Lawrence, Brown, verskillende skrywers uit die South African Law Journal en wetgewing in Suid-Rhodesië.

Sy omskrywing van ,national law” is 'n omskrywing van die regstelsel van Suid-Afrika. Hy verklaar dan ook dat ,the national law of South Africa is founded almost entirely upon a system of law known as RomanDutch Law" (b. 1). Die knoop lê nie net by die woordjie ,almost" nie, maar juis ook by die „Roman-Dutch Law”. Die bronne waarop hy hom in die eerste dertig bladsye van sy werk beroep, is allermins almal ,, RomanDutch"-en tog word hulle deur hom gebruik om ons nasionale reg, hoofsaaklik Romeins-Hollandse reg, te verduidelik. Waar moet die grens getrek word? Indien ons ,national law" dan ,,almost entirely" gegrond is op die Romeins-Hollansde regstelsel, bly die vraag myns insiens nog: presies waarop is dit inderdaad gegrond?

Maar nog meer. „Die Suid-Afrikaanse reg” is, so gesien, beslis nie sinoniem met ,die Romeins-Hollandse reg" nie. Dit is slegs negatief gestel. Die antwoord moet positief wees. Dit is net so moeilik om te sê wat ons onder die Suid-Afrikaanse reg moet verstaan as wat dit moeilik is om te sê wat ons onder Romeins-Hollandse reg verstaan. Die een skrywer sal Glück as bron aanhaal; die ander sal daarteen beswaar maak omdat hy nie tot die groep Romeins-Hollandsregtelike skrywers gereken kan word nie. 'n Derde skrywer sal sê al die Romeins-Hollandse skrywers het maar net opinies oor die reg gegee en daarom is dit moontlik om selfs die onbekendste onder hulle aan te haal wanneer die reg vandag gespreek moet word!

Teenoor Wille met sy oorvloed van bronne om ",national law" te omskryf en te verduidelik, vind ons prof. L. J. du Plessis met feitlik geen bronne deur hom genoem nie. In sy ,Inleiding tot die algemene regsleer' het ons wel nie so 'n handboek soos dié van Wille nie, maar net soos Wille juis „die reg" en veral ook dan ,national law" moes bepaal, so moes prof. Du Plessis, om by die behandeling van wat hy noem ,staatlike reg" te kom, 
ook bepaal wat ,die reg” beteken. En hy moes dit veral vir die Suid-Afrikaanse student doen.

Van die bronne waarop Wille hom beroep, noem prof. Du Plessis "positivisties-analities" (Austin en Holland), of ,histories-positivisties" (Maine). Hy self verklaar (op b. 6): „Maar as ons spreek van ,die reg", dan bedoel ons net een iets en as ons dit nog duideliker wil maak, spreek ons van ,die positiewe reg', d.w.s. die neergelegde of geldende reg." Dit spreek vanself dat as ons bv. van geldende reg praat, dan dink ons ook aan reg wat nie geld nie. Deur net na die geldende reg te kyk, kan ons so beslis nie tot die wese van die reg deurdring nie. (Dit het prof. Du Plessis ook nie in genoemde werk beoog nie, hoewel hy in sy werk wys op teorië omtrent 'n reg wat geen positiewe gelding het nie, soos bv. die natuurreg).

Maar vir daardie geldende of positiewe reg vereis prof. Du Plessis 'n bepaalde geldingsgebied (b. 8). Hy noem dit egter nie noodwendig of net die gebied van 'n bepralde staat nie, hoewel mens so van die Suid-Afrikaanse reg sou kon praat. „Samevattend kan ons dus sê dat die reg (as regsorde of dusgenoemde, objektiewe reg of juridiese wetstelsel) die sisteem van norme is wat uit Godgestelde beginsels gepositiveer is deur die wil van bevoegde vormingsorgane in die verskillende samelewingskringe in onderlinge korrelasic, met bepaalde geldingsgebied en geldingstyd, waardeur langs die weg van afbakening, toelating en magting, gebod en verbod, ens., ' $n$ vereffening van belange in die samelewing verseker word deurdat bepaalde vergeldingsgevolge verbind word aan bepaalde vergeldingsgronde, en dit wel met die groots moontlike mate van algemeenheid en sekerheid." Hierdie omskrywing het hy aangepas, soos hy verklaar, by dié van Dooyeweerd (Wijsbegeerte der Wetsidee, II, b. 338), en hoewel dit ook 'n omskrywing van „objektiewe reg" genoem kan word, verkies hy nie die woorde objektiewe reg nie, maar praat hy liefs van ,die regsorde". Tegelykertyd toon dit 'n bepaalde standpunt in verband met die inhoud en betekenis van die woorde „subjektiewe reg", omdat hy hier met 'n belang werk en nie met die wil nie.

Vergelyk ons nou hierdie omskrywings met mekaar, dan is die verskil opvallend. Maar is prof. Du Plessis se omskrywing van ,die reg” nou wel "Suid-Afrikaans"? Weliswaar is die omskrywing reformatories-Christelik of Calvinisties, maar is „die Suid-Afrikaanse reg" dit? Met die SuidAfrikaanse reg hoofsaaklik gegrond op die Romeins-Hollandse regstelsel, kan nie verklaar word dat hierdie omskrywing Suid-Afrikaans is nie, want die Romeins-Hollandse regstelsel staan in baie groot mate in die teken van die teorie van die natuurreg. Dit doen egter nie af aan die vraag nie of 
met hierdie omskrywing juis beklemtoon is dat ons óf ' $n$ keuse tussen rigtings moet maak- of ons eie inslaan.

Wanneer Wille (op b. 14) verklaar: „Positive or national law in any particular state is .... law made by, or approved of, and enforced by the Government of that state," dan skep hy die indruk dat die staat vir hom alles is wat regskepping en regshandhawing betref. Die staat is vir prof. Du Plessis slegs een van die samelewingskringe, slegs een van die bevoegde vormingsorgane, en vanself ook slegs een van die vergeldingskringe. Mens sou daarby die vraag kon stel of daar juis altyd 'n bepaalde samelewingskring as vergeldingskring aanwesig moet wees om die reg te handhaaf. Die verskil tussen die twee se opvattings blyk egter duidelik.

Voeg Wille aan sy uitlating toe: „There are several methods in which national laws are made; in some of these methods the Government participate directly and in others indirectly," dan skyn dit nog of hy die staat in alle geval aanwesig wil hê by die vorming van die reg. Dit is nie soos prof. Du Plessis die vorming sien nie.

Met slegs hierdie twee skrywers oor die Suid-Afrikaanse reg, blyk nou al dadelik die probleem waarvoor ons staan. Albei het regstelsels omskryf, dit ,die reg" genoem. Albei wil dit aan die Suid-Afrikaanse student se verstand bring wat laasgenoemde hier by ons onder die begrip moet verstaan. Onmiddellik ondervind die student egter by elk van die skrywers dat die onderskeie omskrywings die resultaat is van 'n bepaalde uitgangspunt. Daardie uitgangspunt bring nie net metodiese verskille in die stofbehandeling mee nie, maar ook verskille wat die opvattings rakende vorming, handhawing, vinding, toepassing, werking, verwerkliking, wese of grondslae van die reg betref.

Nou moet noodwendig die vraag gestel word: wat moet in diè verband gedoen word? Het die tyd nie aangebreek nie dat ons in Suid-Afrika begin met 'n eiesoortige ondersoek na ons reg, na die bronne daarvan, na die grondslae daarvan en na die rigting waarheen ons dit wil laat ontwikkel? Myns insiens is die tyd ryp daarvoor.

Meer as driehonderd jaar reeds handhaaf ons sogenaamd die RomeinsHollandse reg. In die loop van hierdie tyd het allerlei invloede op ons en ons reg ingewerk. In die toekoms sal dieselfde en ook ander invloede hul stempel op ons en ons reg afdruk. Dit alles het gebeur, en sal ook in die toekoms net so gebeur, sonder dat ons ons eie reg ken, indien ons nie nou begin om te soek na die antwoord op die vraag: presies wat kenmerk ons land se reg? 
Elders skryf prof. Du Plessis oor die feit dat ons tot sover tevergeefs soek na ' $n$ behoorlike behandeling van bv. 'n regsbronneteorie by ons moderne skrywers. Gebrek aan sodanige teorie bring uit die aard van die saak mee dat ons geen duidelikheid het oor ons regsbronne nie, allermins duidelikheid oor ons regsreëls. Daar is natuurlik diegene wat meen dat ons instellings in ons reg kan en moet handhaaf sonder dat ons enigsins ' $n$ teorie oor daardie instellings hoef te hê, maar dit is myns insiens verkeerd om so te argumenteer.

Om tot die kern van ons probleme deur te dring, meen ek dat die eerste taak wat aangepak moet word, is om vir onsself behoorlike rekenskap te gee van juis ons regsbronne. Om egter uit te maak wat ons regsbronne is, moet allereers duidelikheid verkry word oor die begrip regsbron. Antwoord op laasgenoemde vraag moet juis nie net gesoek word in wat ons vooropstel as ons regsbronne nie. Inteendeel, die antwoord moet gesoek word ook in die lig van ons godsdiens, ons kultuurgeskiedenis en ons eie lewensen wêreldbeskouing. 'n Eiesoortige filosofie, en veral dan ook 'n eie regsfilosofie moet in die soeke na die antwoord dus sterk faktore wees. 'n Ontsaglik wye veld sal egter gedek moet word voor ons behoorlike antwoorde op al ons probleme kan gee. Die taak moet ons nie afskrik nie, want ons is dit aan ons verlede, onsself en ons toekoms verskuldig om dit aan te pak.

H. L. SWANEPOEL. 